\title{
Anti-inflammatory Effects of Distylium racemosum Extract in a Mouse Model of Allergic Asthma
}

\section{(ㄷ)(우) $\odot$}

\author{
Authors \\ Jong-Heon Han ${ }^{1}{ }^{*}$, Kyuhee Park ${ }^{2}$, Jong Suk Lee ${ }^{2}$, Yeon-Ju Nam², Jungeun Yang ${ }^{2}$, Myung-Jin Song ${ }^{2}$, Sung-Jin Ko',

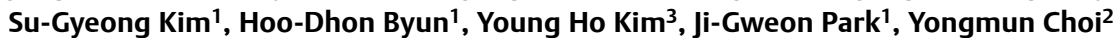

\section{Affiliations}

1 Bio Convergence Center, Jeju Technopark, Jeju, Korea

2 Biocenter, Gyeonggido Business and Science Accelerator, Suwon, Korea

3 College of Pharmacy, Chungnam National University, Daejon, Korea

Key words

Distylium racemosum, Hamamelidaceae, allergic asthma, phosphodiesterase 4, inflammation

received $\quad 18.01 .2018$

revised $\quad 11.03 .2018$

accepted 22.03.2018

Bibliography

DOI https://doi.org/10.1055/a-0600-9786

Planta Med Int Open 2018; 5: e48-e54

(c) Georg Thieme Verlag KG Stuttgart · New York

ISSN 2509-9264

Correspondence

Dr. Ji-Gweon Park

Bio Convergence Center

Jeju Technopark

16 Sancheondandongkil

Jeju City 63243

Jeju Special Self-Governing Province

Korea

Tel.: + 82/64/720 2350, Fax: + 82/64/7513443

jg0822@jejutp.or.kr
Dr. Yongmun Choi

Biocenter

Gyeonggido Business and Science Accelerator

107 Gwanggyro

Yeongtonggu

Suwon 16229

Korea

Tel.: + 82/31/888 6972, Fax: + 82/31/888 6979

ychoi@gbsa.or.kr

\section{ABSTRACT}

Allergic asthma is a complex disorder characterized by chronic airway inflammation. Patients with asthma often show poor adherence to corticosteroid therapy owing to prominent side effects, which provides a rationale to explore new drug classes with a better safety profile. In this study, we sought to discover natural products that inhibit the activity of phosphodiesterase 4 , which is considered a potential molecular target for antiinflammatory therapy. The screening of a plant extract library led to the identification of Distylium racemosum, which inhibited phosphodiesterase 4 activity in vitro and suppressed lipopolysaccharide-induced inflammatory signaling in cultured cells. In a mouse model of ovalbumin-induced allergic asthma, D. racemosum treatment significantly reduced inflammatory responses in the lung, as well as serum immunoglobulin E levels. Although the active constituents of $D$. racemosum extract and the exact mechanism underlying the in vivo action of $D$. racemosum remain to be elucidated, our results provide a basis for further investigation of $D$. racemosum extract as a novel anti-inflammatory agent for allergic asthma.

\section{Introduction}

Chronic airway inflammation is a characteristic feature of allergic asthma. Asthma is triggered by environmental allergens, and the biological cascades driven by $T$ helper type 2 cells $\left(T_{H} 2\right)$ are suggested to play a central role in the initiation of inflammation [1].

* These authors contributed equally to this work.
The production of inflammatory cytokines [interleukin (IL)-4, IL-5, and IL-13], secretion of immunoglobulin $\mathrm{E}(\mathrm{lgE})$ by activated $B$ cells, and infiltration of inflammatory cells such as eosinophils and macrophages into the airway wall are among the well-established parameters used to evaluate allergic asthma in animal models and humans. Therefore, strategies to suppress airway inflammation have been developed for the treatment of asthma. [2]. 
Many proinflammatory responses, such as superoxide anion generation in eosinophils and the release of tumor necrosis factor alpha (TNF $\alpha$ ) in macrophages, are suppressed by cyclic adenosine monophosphate (CAMP) signaling. Therefore, the isoforms of phosphodiesterases (PDEs), which are expressed in inflammatory cells and catalyze the hydrolysis of CAMP, are potential targets in the treatment of allergic asthma. Specifically, phosphodiesterase 4 (PDE4) is considered the most relevant target, because deficiency of PDE4 isotypes in inflammatory cells and pharmacological inhibition of PDE4 have been shown to alleviate inflammatory responses $[3,4]$. A nonselective PDE inhibitor, theophylline, has been reported to exhibit anti-inflammatory effects, and is used to treat asthma and other respiratory diseases despite its relatively low efficacy and gastrointestinal side effects, such as nausea and diarrhea [5]. Theophylline also has a bronchodilator effect, and its relaxant effect on airway smooth muscles is thought to be mediated by increased cAMP levels.

Natural products have been considered a rich source of new drugs for decades. The multitarget and multifunctional characteristics of natural products would be beneficial in achieving additive or synergistic effects when treating complex diseases such as asthma, which remain inadequately controlled with the currently available therapies. In this study, we endeavored to discover natural products that inhibit the activity of PDE4 and evaluated the effects of the identified natural products on allergic asthma in mice. The efforts led to the identification of Distylium racemosum Siebold \& Zucc. (Hamamelidaceae), which attenuated both inflammatory responses in lung tissues and serum IgE levels in an ovalbumin (OVA)induced asthma model. These results provide a basis for further investigation of $D$. racemosum extract as a novel anti-inflammatory agent for allergic asthma.

\section{Results and Discussion}

Ethanolic (EtOH) extracts prepared from terrestrial plants in Jeju Island (Korea) were screened for their ability to inhibit PDE4 activity in vitro. We tested the extracts at a concentration of $100 \mu \mathrm{g} / \mathrm{mL}$ in duplicate. The extracts that inhibited PDE4 activity by $>80 \%$ relative to the control treatment (dimethyl sulfoxide, DMSO) were subjected to dose-response analysis to validate the desired activity. The results led to the identification of $D$. racemosum as a candidate for further evaluation ( $\vee$ Table $\mathbf{1}$ ).

D. racemosum is an evergreen tree belonging to the Hamamelidaceae family that is distributed in Korea, China, and Japan. Previous studies have shown that $D$. racemosum inhibits the activities of tyrosinase, elastase, and ribonuclease $\mathrm{H}[6,7]$; however, its anti-inflammatory effects have not been reported previously.

To test whether $D$. racemosum extract inhibits PDE activity in tissue culture cells, we used RAW 264.7 macrophage cells in which

- Table 1 Inhibitory effects of samples against the activity of PDE4.

\begin{tabular}{|l|c|}
\hline Sample & $\mathbf{I C}_{\mathbf{5 0}}(\boldsymbol{\mu g} / \mathbf{m L})$ \\
\hline D. racemosum extract & $4.4(2.9 \sim 6.7)^{1}$ \\
\hline Rolipram ${ }^{2}$ & $0.093(0.074 \sim 0.115)^{1}$ \\
\hline $\begin{array}{l}\text { 1The numbers in brackets denote the } 95 \% \text { confidence interval. } \\
\text { 2Rolipram is a reference compound that inhibits PDE4 }\end{array}$ \\
\hline
\end{tabular}

PDE4 is a major cAMP-specific PDE isoform and plays a role in lipopolysaccharide (LPS)-induced signaling $[8,9]$. The cells stably harboring the firefly luciferase reporter gene under the control of CAMP-response elements (CRE-LUC) were treated with either DMSO or the extract $(100 \mu \mathrm{g} / \mathrm{mL})$ for $3 \mathrm{~h}$, and then luciferase activity was measured. We also used a DNA construct encoding the firefly luciferase reporter gene under the control of a basal promoter (TA-LUC) to exclude the possibility that the increased luciferase activity resulted from nonspecific transcriptional activation of the luciferase gene independent of CRE. As expected, the extract increased luciferase activity more than DMSO did; however, the extract had no detectable effect on the luciferase activity derived from the basal promoter ( $\triangleright$ Fig. 1a). These results indicate that luciferase transcription was enhanced by increased cAMP levels.

To explore the anti-inflammatory effect of the extract, RAW 264.7 macrophage cells were exposed to LPS for $6 \mathrm{~h}$ following pretreatment with the extract $(100 \mu \mathrm{g} / \mathrm{mL})$ for $1 \mathrm{~h}$. The TNF $\alpha$ concentration was then measured by enzyme-linked immunosorbent assay (ELISA). As shown in > Fig. 1b, D. racemosum extract suppressed LPS-induced expression of TNF $\alpha$ by $33.6 \%$, but was noncytotoxic to RAW 264.7 cells as determined by MTS assay (data not shown). In addition, $D$. racemosum extract inhibited LPS-induced expression of TNF $\alpha$ to a similar extent as rolipram $(20 \mu \mathrm{M})$. These results are in line with the previous observation that LPS-induced expression of TNF $\alpha$ was attenuated by targeted disruption of the PDE4B gene in monocytes/macrophages [8].

Allergic asthma is associated with the infiltration of inflammatory cells into the airway wall, which is triggered by $\mathrm{T}_{\mathrm{H}} 2$ lymphocyte-driven inflammatory responses $[10,11]$. Therefore, we evaluated the effect of the extract on inflammatory cell recruitment in mice with OVA-induced asthma. Bronchoalveolar lavage (BAL) was used to collect inflammatory cells from lung tissues at $48 \mathrm{~h}$ after the last OVA challenge. The analysis of BAL fluids showed that eosinophil, macrophage, and lymphocyte counts were significantly higher in samples collected from OVA-challenged animals than in those collected from sham-operated mice ( $>$ Fig. 2a). As expected, OVA-induced increases in inflammatory cell counts in BAL fluid were markedly suppressed by the $D$. racemosum extract. At a dose of $60 \mathrm{mg} / \mathrm{kg}$, the extract decreased eosinophil and macrophage counts by 46.7 and $58.3 \%$, respectively ( $\mathbf{F i g}$. 2 a).

Histological examination of the lung tissues revealed that inflammatory cell counts in peribronchiole and perivascular connective tissues increased significantly after the OVA challenge and were higher than the respective counts in the sham-operated group $(p<0.001)$. The results also showed that $D$. racemosum extract administration resulted in the suppression of inflammatory cell influx into the lung tissues. At doses of 30 and $60 \mathrm{mg} / \mathrm{kg}$, the extract decreased the inflammatory index by 27.7 and $39.8 \%$, respectively ( $\vee$ Fig. 2b, c).

We next measured the concentration of inflammatory cytokines (IL-5 and IL-13) in BAL fluids by ELISA. As was the case for the other parameters, OVA sensitization/challenge significantly enhanced the production of inflammatory cytokines ( $p<0.001$ when compared to the sham-operated group). Moreover, OVA-induced increases in IL-5 and IL-13 levels were reduced by 39.1 and $26.4 \%$, respectively, by $60 \mathrm{mg} / \mathrm{kg}$ D. racemosum ( $\triangleright \mathbf{F i g . ~} \mathbf{3 a}$, b). 
IgE is expressed in activated B lymphocytes. It binds to Fc receptors on mast cells and basophils, and triggers their degranulation and the release of inflammatory mediators, such as histamine and leukotrienes $[12,13]$. The expression of $\mathrm{IgE}$ is affected by $T_{H} 2$ cytokines such as IL-4 and IL-13 [14, 15]. Therefore, we evaluated the effect of $D$. racemosum on serum IgE levels in a mouse model of allergic asthma. At $48 \mathrm{~h}$ after the last OVA challenge, blood samples were collected from the postcava, and the sera were analyzed for the levels of OVA-specific IgE by ELISA. The results showed that the level of OVA-specific IgE was significantly enhanced and higher in the OVA-sensitized/challenged group than in the sham-operated group $(p<0.001)$. However, OVA-induced increases in serum IgE levels were attenuated by the $D$. racemosum extract. At doses of 30 and $60 \mathrm{mg} / \mathrm{kg}$, the extract decreased OVA-induced serum IgE by 38.1 and $47.2 \%$, respectively ( $\vee$ Fig. $3 c$ ).

Dexamethasone exerts an anti-inflammatory effect by suppressing the expression of inflammatory cytokines and chemokines during the early phase of inflammation [16]. Therefore, we used dexamethasone as the reference compound rather than a PDE4 inhibitor in the animal model of allergic asthma, although the use of dexamethasone may not correlate with the pharmacological inhibition of PDE4. In our study, the reduction in inflammatory responses in OVA-challenged mice by $D$. racemosum treatment was not as profound as that observed with dexamethasone. However, the efficacy of $D$. racemosum in suppressing inflammatory responses appears to be comparable to that resulting from PDE4B deficiency in OVA-challenged mice [4], although a direct comparison of the two results may not be appropriate because the sensitization protocol and/or species used could affect the experimental outcome. It remains to be demonstrated whether improvement in the measured clinically relevant parameters of asthma correlates with the ability of $D$. racemosum to inhibit PDE4 activity in vivo.

In an effort to identify the active constituents that contribute to the PDE4 inhibitory activity of $D$. racemosum extract in vitro, we first enriched the active constituents from the crude extract. Because $D$. racemosum extract was prepared from both leaves and twigs, we prepared separate EtOH extracts of the two plant parts. The extracts were then subjected to successive solvent fractionation using n-hexane, ethyl acetate (EtOAc), and butanol (BuOH). Each fraction was then evaluated for its inhibitory effect on PDE4.

The results showed that EtOAc fractions exhibited a stronger inhibitory activity than the other fractions and crude extracts ( Table 2), indicating that EtOAc fractions were good sources for the isolation of active constituents. We next aimed to identity the major compounds in EtOAc fractions using a dereplication strategy involving liquid chromatography-mass spectrophotometry and database searches [17]. Dereplication led to the identification of 13 compounds ( $\triangleright$ Fig. 4 and $\triangleright$ Table 3 ), including catechin, ethyl gallate, nicotiflorin, quercitrin, kaempferin, and quercetin, which were already isolated from $D$. racemosum extracts in previous studies $[6,7]$. However, none of the identified compounds exerted a potent inhibitory effect on PDE4 activity. Although quercetin has been reported to inhibit PDE4 purified from guinea pig lungs with an $\mathrm{IC}_{50}$ value of $9.9 \pm 2.5 \mu \mathrm{M}$ [18], we failed to observe a potent inhibitory activity of quercetin against human PDE4 in our assay conditions $\left(I C_{50}>20 \mu \mathrm{M}\right)$. Although both human and guinea pig PDE4 share a high degree of sequence similarity in the active site, the

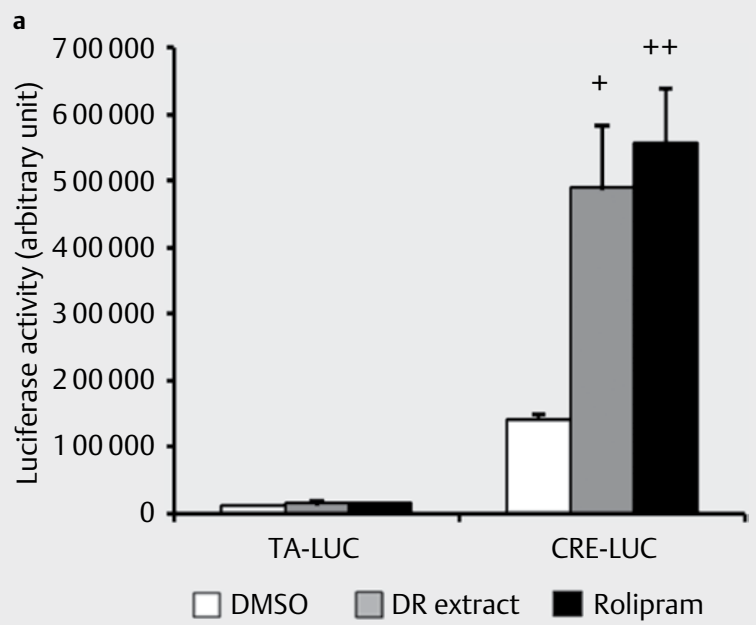

b

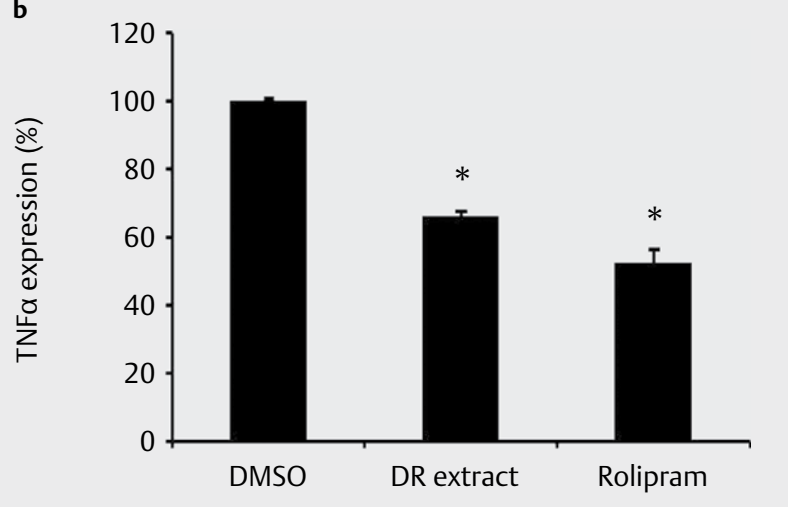

- Fig. 1 Anti-inflammatory effect of $D$. racemosum in cultured cells. a Inhibition of PDE activity by $D$. racemosum in RAW 264.7 cells stably harboring a luciferase reporter gene under the control of either a basal promoter (TA-LUC) or cyclic AMP response elements (CRE-LUC). Firefly luciferase activity was measured after treating the cells with either DMSO $(0.25 \%)$ or the extract $(100 \mu \mathrm{g} / \mathrm{mL})$ for $3 \mathrm{~h}$. Rolipram $(20 \mu \mathrm{M})$ was used as the reference compound. Each column represents the mean $\pm S D(n=3) .{ }^{+} P<0.05$, DMSO vs. DR extract; ${ }^{++} p<0.01$, DMSO vs. rolipram. DR, D. racemosum. $\mathbf{b}$ Effects of $D$. racemosum on LPS-induced TNF $\alpha$ expression in RAW 264.7 cells. The cells were pretreated with either DMSO $(0.25 \%)$ or the extract $(100 \mu \mathrm{g} / \mathrm{mL})$ for $1 \mathrm{~h}$, and then incubated with LPS for another $6 \mathrm{~h}$. The conditioned media were analyzed for TNF $\alpha$ levels by ELISA. Rolipram was used as the reference compound. Data are expressed as percentages of the data obtained for the DMSO-treated cells (mean $\pm S D, n=3$ ). ${ }^{*} P<0.001$, DMSO vs. DR extract or rolipram.

discrepancy in the effects of quercetin could possibly be attributed to variation in amino acid residues in the active site, which finetunes the affinity for quercetin.

Our results indicated that unidentified compounds present in moderate quantities could have significantly contributed to the in vitro bioactivity of $D$. racemosum. Alternatively, minor constituents in the extract could have exerted potent inhibitory activity against PDE4. Further investigations, including bioassay-guided column fractionation of the EtOAc fractions and purification of unidentified compounds, are necessary to elucidate the constituents responsible for inhibiting PDE4 activity. 

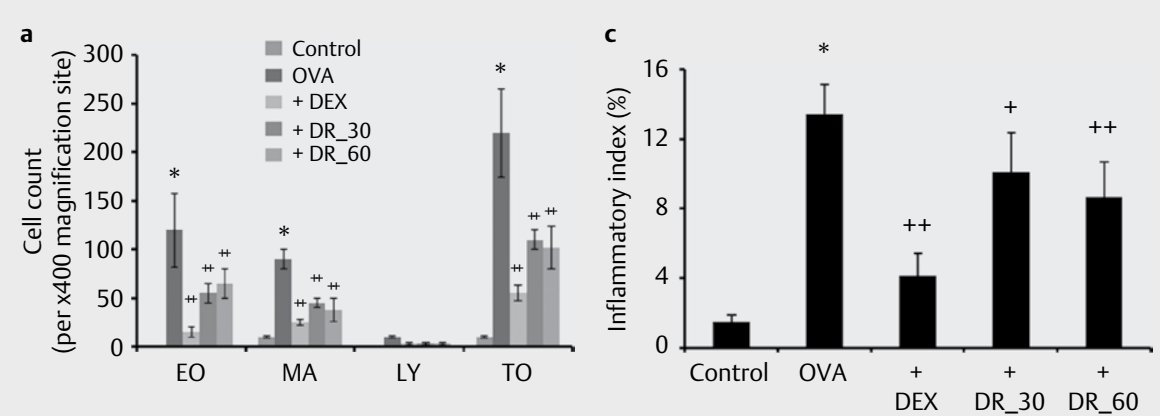

b
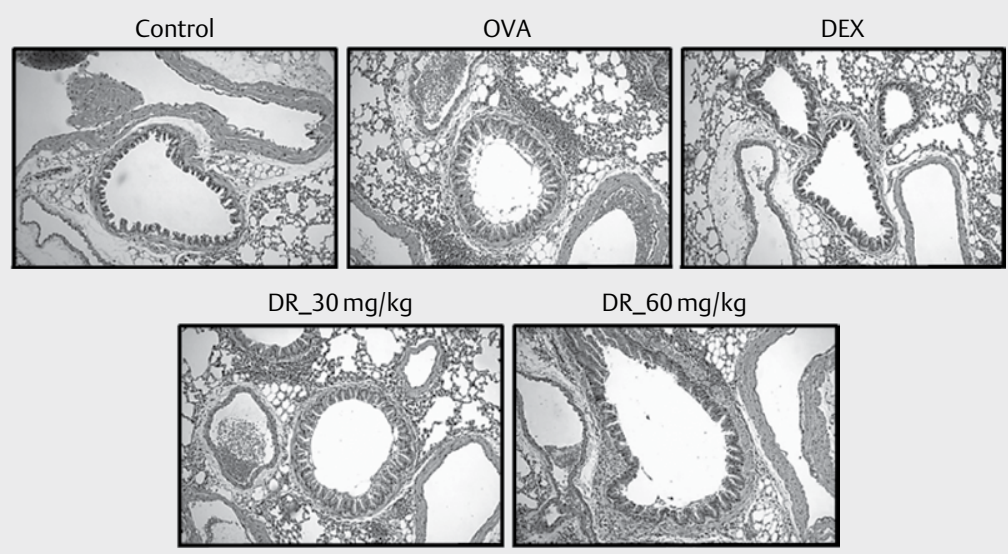

\begin{abstract}
- Fig. 2 Effects of $D$. racemosum extract on inflammatory cell influx into lung tissues in a mouse model of allergic asthma. a At $48 \mathrm{~h}$ after the last OVA challenge, BAL fluid samples were collected from separate groups of mice and analyzed for the inflammatory cell count using Diff-Quik reagents. The cells were differentially counted under a microscope. Data are expressed as the mean $\pm S D(n=7) .{ }^{*} P<0.001$, control vs. asthma model (OVA); ${ }^{++} \mathrm{p}<0.01$, OVA vs. OVA + DEX or OVA + DR. EO, eosinophil; MA, macrophage; LY, lymphocyte; TO, total cells. b At $48 \mathrm{~h}$ after the last OVA challenge, the lung tissues were subjected to hematoxylin and eosin staining, and representative images from each group are shown. C The images were analyzed for inflammatory cell infiltration in the airways using a scoring method [20]. Dexamethasone $(3 \mathrm{mg} / \mathrm{kg})$ was used as the reference compound. Data are expressed as the mean $\pm S D(n=7)$. ${ }^{*} P<0.001$, control vs. asthma model $(\mathrm{OVA}) ;{ }^{+} p<0.05,{ }^{++} \mathrm{p}<0.01, \mathrm{OVA}$ vs. OVA + DEX or $\mathrm{OVA}+\mathrm{DR}$.
\end{abstract}

In conclusion, although the efficacy of $D$. racemosum was not comparable to that of dexamethasone in the OVA-induced asthma model, $D$. racemosum markedly attenuated both inflammatory responses in lung tissues and serum IgE levels. Although the exact mechanism of action of $D$. racemosum in vivo is yet to be elucidated, our results provide a basis for further investigation of $D$. racemosum extract as a novel anti-inflammatory agent for allergic asthma.

\section{Materials and Methods}

\section{Reagents}

Dexamethasone (purity $>98 \%$ by HPLC), rolipram (purity $>98 \%$ by HPLC), and all other standard compounds were purchased from Sigma-Aldrich Corporation.

\section{Plant materials and preparation of extracts}

The leaves and twigs of $D$. racemosum were collected from Jeju Island (Korea) in May 2014, and authenticated by curators at Jeju Technopark (Jeju, Korea). A voucher specimen (voucher no. JT04140) was deposited at the herbarium at Jeju Technopark. Dried samples $(100 \mathrm{~g})$ were powdered and macerated in $70 \% \mathrm{EtOH}(1 \mathrm{~L})$ at room temperature for $12-24 \mathrm{~h}$. The extracts obtained were fil- tered and evaporated under reduced pressure. The residue was then dried to obtain a powdered material.

\section{Phosphodiesterase assay}

Recombinant human PDE4A was purchased from BPS Bioscience. PDE activity was measured using the LANCE Ultra cAMP Kit (PerkinElmer). In brief, aliquots of the enzyme were preincubated with either DMSO or the extracts for $10 \mathrm{~min}$ at $25^{\circ} \mathrm{C}$ in a buffer containing $1 \times$ Hanks' balanced salt solution, 5 mM HEPES ( $\mathrm{pH} 7.4), 3 \mathrm{mM}$ $\mathrm{MgCl}_{2}$, and $0.1 \%$ bovine serum albumin. After the addition of $12 \mathrm{nM}$ of CAMP, the reaction was allowed to proceed for $30 \mathrm{~min}$, followed by incubation with Eu-cAMP tracer and ULight-anti-cAMP for $1 \mathrm{~h}$. Time-resolved fluorescence energy transfer signals were detected using the EnVision Multilabel Plate Reader (PerkinElmer).

\section{Establishment of cell lines stably harboring a luciferase reporter gene construct}

RAW 264.7 cells $\left(5 \times 10^{6}\right.$ cells/well) in a 60 -mm culture dish were transfected with a DNA construct $(3 \mu \mathrm{g})$ encoding a luciferase reporter gene under the control of either CAMP-response elements (CRE-LUC) or the basal promoter (TA-LUC) by using FuGENE HD (Promega) according to the manufacturer's protocol. The cells were divided at a 1:20 dilution $24 \mathrm{~h}$ after transfection and further incu- 


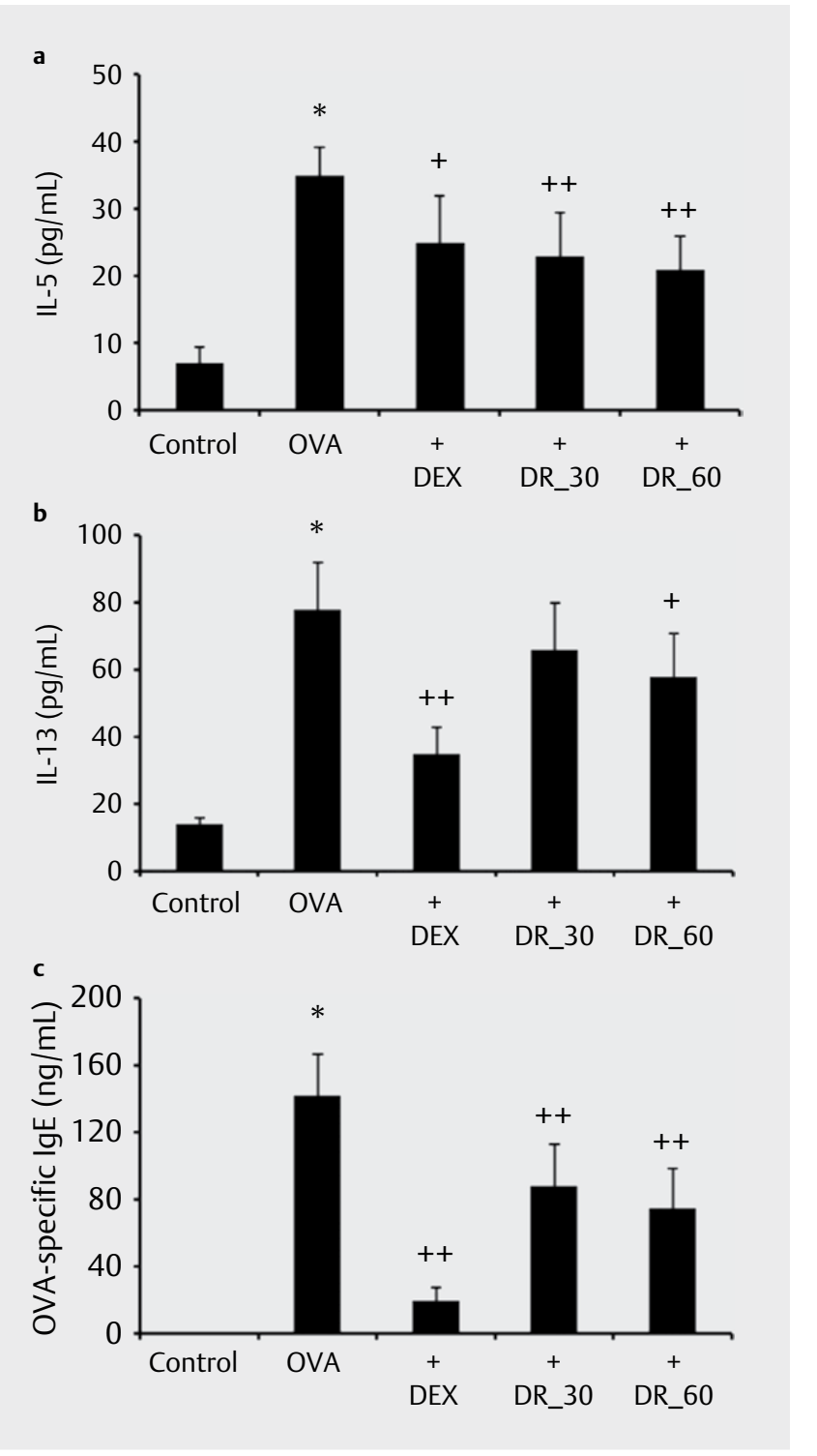

- Fig. 3 Effects of $D$. racemosum extract on the levels of inflammatory cytokines in BAL fluid and OVA-specific IgE in serum. BAL fluids were collected from separate groups of mice at $48 \mathrm{~h}$ after the last OVA challenge and analyzed for the levels of $\mathbf{a} \mathrm{IL}-5$ and $\mathbf{b} \mathrm{IL}-13$ by ELISA. c Blood samples were collected from separate groups of mice at $48 \mathrm{~h}$ after the last OVA challenge and analyzed for OVA-specific IgE levels by ELISA. Dexamethasone $(3 \mathrm{mg} / \mathrm{kg}$ ) was used as the reference compound. Data are expressed as the mean $\pm S D(n=7) .{ }^{*} P<0.001$, control vs. asthma model (OVA); ${ }^{++} p<0.01$, OVA vs. OVA + DEX or $\mathrm{OVA}+\mathrm{DR}$.

bated in medium containing $50 \mathrm{\mu g} / \mathrm{mL}$ hygromycin before individual colonies were picked and expanded into cell lines.

\section{Analysis of the ethyl acetate fraction derived from the Distylium racemosum whole extract by UHPLC- high-resolution tandem mass spectrometry}

The analysis was performed as previously described [19] with minor modifications. Briefly, D. racemosum extract was separated on an ACQUITY UPLC BEH C 18 column $(2.1 \times 150 \mathrm{~mm}, 1.7 \mu \mathrm{m}$; Waters Co. $)$.
- Table 2 Inhibitory effects of the solvent fractions derived from the EtOH extract of the leaves or twigs of $D$. racemosum.

\begin{tabular}{|l|l|c|}
\hline Solvent Fractions & \multicolumn{2}{|c|}{$\mathbf{I C}_{\mathbf{5 0}}$ ( $\left.\boldsymbol{\mu g} / \mathbf{m L m L}\right)$} \\
\hline \multirow{4}{*}{ Leaf } & $n$-Hexane & $>100$ \\
\cline { 2 - 3 } & Ethyl acetate & $2.4(1.6 \sim 3.6)^{1}$ \\
\cline { 2 - 3 } & Butanol & $4.9(3.2 \sim 7.6)^{1}$ \\
\cline { 2 - 3 } & $\mathrm{H}_{2} \mathrm{O}$ & $13.7(8.4 \sim 22.4)^{1}$ \\
\hline \multirow{3}{*}{ Twig } & $n$-Hexane & $10.1(5.0 \sim 20.0)^{1}$ \\
\cline { 2 - 3 } & Ethyl acetate & $1.6(1.2 \sim 2.1)^{1}$ \\
\cline { 2 - 3 } & Butanol & $5.5(3.6 \sim 8.3)^{1}$ \\
\cline { 2 - 3 } & $\mathrm{H}_{2} \mathrm{O}$ & $8.0(5.0 \sim 12.7)^{1}$ \\
\hline
\end{tabular}

${ }^{1}$ The numbers in brackets denote the $95 \%$ confidence interval.

The mobile phase comprised water containing $0.1 \%$ formic acid $(A)$ and acetonitrile (B) and was run in gradient mode as follows: $5 \% \mathrm{~B}$ at $0-1 \mathrm{~min}, 5-55 \% \mathrm{~B}$ at $1-15 \mathrm{~min}, 55-100 \% \mathrm{~B}$ at $15-16 \mathrm{~min}$, and $100 \% \mathrm{~B}$ at $16-20 \mathrm{~min}$. Each compound was detected using a photodiode array at $200-600 \mathrm{~nm}$. High-resolution mass spectra were acquired on an LTQ Orbitrap XL and analyzed with Xcalibur software (Thermo Fisher Scientific).

\section{Animals}

All animal experiments were approved by the Institutional Animal Care and Use Committee at the Korea Research Institute of Bioscience and Biotechnology (Daejon, Korea) with approval number KRIBB-AEC-14092 (Dated June 11, 2014). Six-week-old female $\mathrm{BALB} / \mathrm{c}$ mice were purchased from Samtako Bio Korea and maintained under specific pathogen-free conditions for at least 1 week for adaptation.

\section{Mouse model of ovalbumin-induced asthma}

The animals were randomly divided into the following five groups ( $n=7$ in each group): sham-operated, OVA-induced asthma model (sensitized and challenged with OVA), asthma model treated with dexamethasone $(3 \mathrm{mg} / \mathrm{kg})$, and asthma model treated with $D$. racemosum (30 or $60 \mathrm{mg} / \mathrm{kg}$ ) groups. The mice were injected intraperitoneally with $20 \mu \mathrm{g}$ of OVA complexed with $2 \mathrm{mg}$ of aluminum hydroxide in $200 \mu \mathrm{L}$ of phosphate buffered saline (PBS, $\mathrm{pH} 7.4$ ) on days 0 and 14 . For the OVA challenge, the animals were exposed to an aerosol of $1 \%(\mathrm{w} / \mathrm{v})$ OVA in PBS for 30 min using an ultrasonic nebulizer (NE-U12; Omron) on days 21, 22, and 23. D. racemosum extract or dexamethasone was orally administered daily for 6 days, beginning 3 days before the first OVA challenge.

\section{Bronchoalveolar lavage fluid analysis}

At $48 \mathrm{~h}$ after the last OVA challenge, the mice were euthanized and BAL fluid was collected following a tracheotomy. After centrifugation of the collected BAL fluid $(1.4 \mathrm{~mL}$ in PBS) at $400 \times \mathrm{g}$ for $10 \mathrm{~min}$, the supernatants were kept at $-70{ }^{\circ} \mathrm{C}$ until analysis of cytokine levels. For each specimen, the pellet was suspended in $0.4 \mathrm{~mL}$ of PBS, after which a cytospin slide was prepared and stained with Diff-Quik reagents following the manufacturer's instruction (Sysmex). The differential counts of inflammatory cells were analyzed at $400 \times$ magnification. 


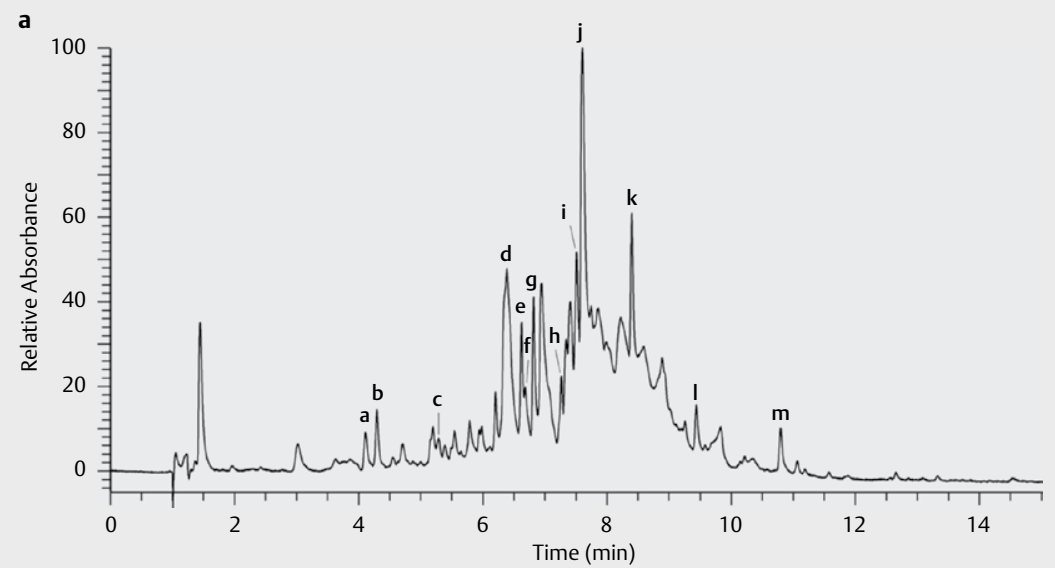

b

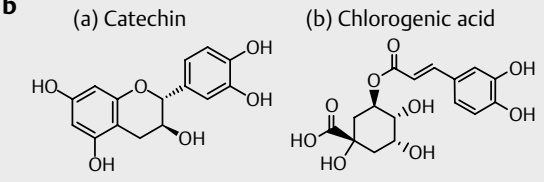

(c) 4-O-Caffeoylquinic acid

(d) Ethyl gallate

(e) Myricitrin

(f) Epicatechin gallate

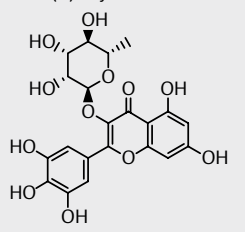

(1)

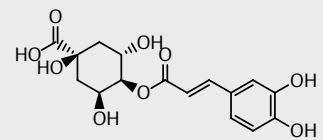<smiles>CCOC(=O)c1cc(O)c(O)c(O)c1</smiles>

(g) Hyperoside (h) Nicotiflorin<smiles></smiles>

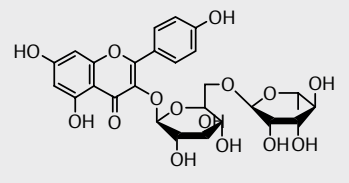

$\begin{array}{ll}\text { (i) Astragalin } & \text { (j) Quercitrin }\end{array}$<smiles>O=C(OC1OC(CO)C(O)C(O)C1O)c1c(-c2ccc(O)cc2)oc2cc(O)cc(O)c12</smiles>

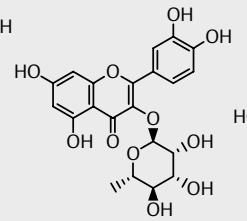

(k) Kaempferin

(I) Quercetin

(m) Kaempferol

- Fig. 4 Analysis of the EtOAc fraction derived from D. racemosum extract. a UHPLC chromatogram of the EtOAc fraction. $\mathbf{b}$ Structures of the identified compounds.

- Table 3 The 13 compounds identified in D. racemosum.

\begin{tabular}{|c|c|c|c|c|c|}
\hline Entry & $\mathbf{R T}(\mathbf{m i n})$ & $\mathbf{m} / \mathbf{z}\left([\mathbf{M}+\mathbf{H}]^{+}\right)$ & Calculated formula & $\Delta \mathbf{p p m}$ & \multicolumn{1}{|c|}{ Identification } \\
\hline $\mathrm{a}$ & 4.11 & 291.0861 & $\mathrm{C}_{15} \mathrm{H}_{15} \mathrm{O}_{6}$ & -0.909 & catechin \\
\hline $\mathrm{b}$ & 4.29 & 355.1021 & $\mathrm{C}_{16} \mathrm{H}_{19} \mathrm{O}_{9}$ & -0.644 & Chlorogenic acid \\
\hline $\mathrm{c}$ & 5.31 & 355.1022 & $\mathrm{C}_{16} \mathrm{H}_{19} \mathrm{O}_{9}$ & -0.362 & 4-O-Caffeoylquinic acid \\
\hline $\mathrm{d}$ & 6.39 & 199.0601 & $\mathrm{C}_{9} \mathrm{H}_{11} \mathrm{O}_{5}$ & -0.201 & Ethyl gallate \\
\hline $\mathrm{e}$ & 6.63 & 465.1022 & $\mathrm{C}_{21} \mathrm{H}_{21} \mathrm{O}_{12}$ & -1.145 & Myricitrin \\
\hline $\mathrm{f}$ & 6.69 & 443.0968 & $\mathrm{C}_{22} \mathrm{H}_{19} \mathrm{O}_{10}$ & -1.158 & Epicatechin gallate \\
\hline $\mathrm{g}$ & 6.82 & 465.1022 & $\mathrm{C}_{21} \mathrm{H}_{21} \mathrm{O}_{12}$ & -1.145 & Hyperoside \\
\hline $\mathrm{h}$ & 7.27 & 595.1652 & $\mathrm{C}_{27} \mathrm{H}_{30} \mathrm{O}_{15}$ & -1.002 & Nicotiflorin \\
\hline $\mathrm{i}$ & 7.51 & 449.1073 & $\mathrm{C}_{21} \mathrm{H}_{21} \mathrm{O}_{11}$ & -1.153 & Astragalin \\
\hline $\mathrm{j}$ & 7.61 & 449.1075 & $\mathrm{C}_{21} \mathrm{H}_{21} \mathrm{O}_{11}$ & -0.708 & Quercitrin \\
\hline $\mathrm{k}$ & 8.40 & 433.1125 & $\mathrm{C}_{21} \mathrm{H}_{21} \mathrm{O}_{10}$ & -0.885 & Kaempferin \\
\hline $\mathrm{I}$ & 9.44 & 303.0498 & $\mathrm{C}_{15} \mathrm{H}_{11} \mathrm{O}_{7}$ & -0.525 & Quercetin \\
\hline $\mathrm{m}$ & 10.80 & 287.0547 & $\mathrm{C}_{15} \mathrm{H}_{11} \mathrm{O}_{6}$ & -1.061 & Kaempferol \\
\hline
\end{tabular}




\section{Statistical analysis}

Statistical significance was calculated via one-way analysis of variance followed by Dunnett's multiple comparison test using GraphPad Prism. Data are expressed as the mean \pm standard deviation (SD). $\mathrm{P}<0.05$ was considered statistically significant.

\section{Acknowledgements}

This work was supported by the Ministry of Trade, Industry and Energy through the Inter-ER Cooperation Projects (R0002016) and Support Program for Creative Industry Institutes (R0003950), and by the National Research Foundation of Korea (NRF) grant funded by the Korea government (MIST) (No. 2016R1A5A2007009). We would also like to acknowledge the generous financial support from the Gyeonggi provincial government.

\section{Conflict of Interest}

The authors declare no conflict of interest.

\section{References}

[1] Shinkai K, Mohrs M, Locksley RM. Helper T cells regulate type-2 innate immunity in vivo. Nature 2002; 420: 825-829

[2] Reddel HK, Busse WW, Pedersen S, Tan WC, Chen YZ, Jorup C, Lythgoe D, O'Byrne PM. Should recommendations about starting inhaled corticosteroid treatment for mild asthma be based on symptom frequency: A post-hoc efficacy analysis of the START study. Lancet 2017; 389: 157-166

[3] Page CP, Spina D. Selective PDE inhibitors as novel treatments for respiratory diseases. Curr Opin Pharmacol 2012; 12: 275-286

[4] Jin SL, Goya S, Nakae S, Wang D, Bruss M, Hou C, Umetsu D, Conti M. Phosphodiesterase $4 \mathrm{~B}$ is essential for $\mathrm{T}(\mathrm{H}) 2$-cell function and development of airway hyperresponsiveness in allergic asthma. J Allergy Clin Immunol 2010; 126: 1252-1259.e12

[5] Barnes PJ. Theophylline. Pharmaceuticals (Basel) 2010; 3: 725-747

[6] Ko RK, Kim GO, Hyun CG, Jung DS, Lee NH. Compounds with tyrosinase inhibition, elastase inhibition and DPPH radical scavenging activities from the branches of Distylium racemosum Sieb. et Zucc. Phytother Res 2011; 25: 1451-1456
[7] Kim JA, Yang SY, Wamiru A, McMahon JB, Le Grice SF, Beutler JA, Kim YH. New monoterpene glycosides and phenolic compounds from Distylium racemosum and their inhibitory activity against ribonuclease H. Bioorg Med Chem Lett 2011; 21: 2840-2844

[8] Jin SL, Lan L, Zoudilova M, Conti M. Specific role of phosphodiesterase $4 \mathrm{~B}$ in lipopolysaccharide-induced signaling in mouse macrophages. J Immunol 2005; 175: 1523-1531

[9] Jin SL, Conti M. Induction of the cyclic nucleotide phosphodiesterase PDE4B is essential for LPS-activated TNF-alpha responses. Proc Natl Acad Sci U S A 2002; 99: 7628-7633

[10] Humbles AA, Lloyd CM, McMillan S], Friend DS, Xanthou G, McKenna EE, Ghiran S, Gerard NP, Yu C, Orkin SH, Gerard C. A critical role for eosinophils in allergic airways remodeling. Science 2004; 305 : 1776-1779

[11] Kelly-Welch AE, Hanson EM, Boothby MR, Keegan AD. Interleukin-4 and interleukin-13 signaling connections maps. Science 2003; 300: 1527-1528

[12] Gould HJ, Sutton BJ, Beavil AJ, Beavil RL, McCloskey N, Coker HA, Fear D, Smurthwaite L. The biology of IGE and the basis of allergic disease. Annu Rev Immunol 2003; 21: 579-628

[13] Garman SC, Wurzburg BA, Tarchevskaya SS, Kinet JP, Jardetzky TS. Structure of the Fc fragment of human IgE bound to its high-affinity receptor Fc epsilonRI alpha. Nature 2000; 406: 259-266

[14] Ramadani F, Bowen H, Upton N, Hobson PS, Chan YC, Chen JB, Chang TW, McDonnell JM, Sutton BJ, Fear DJ, Gould HJ. Ontogeny of human IgE-expressing B cells and plasma cells. Allergy 2017; 72: 66-76

[15] Chung KF. Targeting the interleukin pathway in the treatment of asthma. Lancet 2015; 386: 1086-1096

[16] Postma DS, Rabe KF. The Asthma-COPD Overlap Syndrome. N Engl ] Med 2015; 373: 1241-1249

[17] Nikolic D, Godecke T, Chen SN, White J, Lankin DC, Pauli GF, van Breemen RB. Mass spectrometric dereplication of nitrogen-containing constituents of black cohosh (Cimicifuga racemosa L.). Fitoterapia 2012; 83: 441-460

[18] Ko WC, Shih CM, Lai YH, Chen JH, Huang HL. Inhibitory effects of flavonoids on phosphodiesterase isozymes from guinea pig and their structure-activity relationships. Biochem Pharmacol 2004; 68: 2087-2094

[19] Park K, Lee JS, Choi JS, Nam YJ, Han JH, Byun HD, Song MJ, Oh JS, Kim SG, Choi Y. Identification and Characterization of Baicalin as a Phosphodiesterase 4 Inhibitor. Phytother Res 2016; 30: 144-151

[20] Oh SR, Lee MY, Ahn K, Park BY, Kwon OK, Joung H, Lee J, Kim DY, Lee S, Kim JH, Lee HK. Suppressive effect of verproside isolated from Pseudolysimachion longifolium on airway inflammation in a mouse model of allergic asthma. Int Immunopharmacol 2006; 6: 978-986 